\title{
Phytochemical Analysis and Chemical Fingerprinting of Seeds of Abrus Precatorius L.
}

\author{
AMIT SARAF ${ }^{1}$, APARNA SARAF $^{2}$ and ALKA CHATURVEDI ${ }^{1}$ \\ ${ }^{1}$ Department of Botany, RTM Nagpur University, Nagpur, India \\ ${ }^{2}$ The Institute of Science, Fort, Mumbai, India \\ aysaraf@gmail.com
}

Received 14 September 2017 / Accepted 3 October 2017

\begin{abstract}
Herbal medicine system has a long tradition and was a reason behind the survival of all ancient civilization. The development in analytical science and growing acceptance of herbals, are pressing for standardized parameters for herbal evaluation. Abrus precatorius L. is an important medicinal plant and one of the highly traded plants in India. Seeds exhibits fertility related activity and are used in Ayurveda, Siddha and Unani systems of medicine. Standardization parameters are studied in $A$. precatorius, as mentioned in various pharmacopoeias and WHO guidelines. Preliminary phytochemical analysis in various solvents was done to reveal the presence of various secondary metabolites. Proximate analysis was performed to evaluate the suitability of dried seed powder as per the global norms. Extractive values and optimization studies will help to develop and improve chemical fingerprinting protocols. HPTLC and FTIR fingerprint results can be employed for the purpose of authentication and identification of the plant under study.
\end{abstract}

Keywords: Abrus precatorius L., Proximate analysis, Extractive value, HPTLC, FTIR

\section{Introduction}

Herbal products are witnessing steady growth in nutraceutical and pharmaceutical industry. Plants are the backbone of folklore and traditional systems of medicine. Therapeutic use of herbals has been well archived by the old Indian and Chinese system of medicines. Use of herbal medicines for curing of diseases is on the rise in developing and developed countries. These herbal products have served as a major source of drugs for centuries and about half of the pharmaceuticals in use today are derived from herbal products. India has witnessed incessant growth in the consumption of herbal raw material in domestic market. The concerns over the efficacy and safety of herbal medicines have turned the major pharmaceutical population towards medicinal plants research. Hence development of suitable technique for phytochemical evaluation and authentication of herbals has gained paramount importance.

Various analytical techniques that are employed to analyze phytochemical aspects of the plant could be a solution to overcome the problems of quality assurance, control and authentication of medicinal plant species ${ }^{1}$. The standardized parameters for the evaluation of 
plants result in universal acceptance of herbal medicines. The method for such analysis and the accepted results are prescribed in various pharmacopoeias and WHO guidelines. Proximate analysis of herbal raw material is an important quality control measure adopted worldwide.

Phytochemical analysis of herbal raw material varies according to the objective of analysis. Preliminary evaluation of secondary metabolites in various extracts, optimization of solvent for extraction and quantitative determination of polar, non-polar extract helps in better result during chemical fingerprinting of herbals.

It has been observed that the chemical fingerprinting technique allows identity establishment to check authenticity of drugs ${ }^{2}$. This has been accepted as a desirable parameter in conventional drug assessment protocols. Further, it is an established fact that the HPTLC fingerprint of botanically authenticated raw material serves as a primary reference against which unknown material can be characterized ${ }^{3,4}$.

Abrus precatorius L. is an important medicinal plant in India with a woody and twinning habit. It belongs to family fabaceae and bears characteristic red and black seeds. The leaves are pinnate and glabrous, with many leaflets arranged in pairs. The plant bears orange-pink flowers, which occur as clusters in short racemes. The plant produces short pods, with 4 to 6 red and black seeds. Seeds of A. precatorius are used for fertility related activity in traditional medicinal system like Ayurveda and Unani. Bioactivity of seed extract as an antifertility agent was reported by pharmacologists in 1970s. Decoction or hot water extract of dried seeds was administered orally as an antifertility and abortifacient agent to prevent conception $^{5-11}$.

Seeds of Abrus precatorius L. are among the most poisonous seeds in the world and contain principle compound, abrine, abrin A, abrin $\mathrm{B}$, abrin $\mathrm{C}$ abricin and abridin ${ }^{12}$. The present work deals with phytochemical analysis and chemical fingerprinting of important medicinal plant, Abrus precatorius L.

\section{Experimental}

The seeds of Abrus precatorius L. were collected from the campus of Rashtrasant Tukdoji Maharaj Nagpur University (RTMNU), Nagpur, Maharashtra, India. The plant material was identified and authenticated at Department of Botany, RTMNU, Nagpur. The plant material was then uniformly grounded using mechanical grinder to make fine powder. The powdered material was stored in an air tight container.

\section{Proximate analysis}

Proximate analysis was done for parameters like foreign organic matter, total ash content, acid insoluble ash, water soluble ash, sulphated ash, loss on drying and determination of crude fibres as per the standard methods mentioned in Ayurvedic Pharmacopoeia of India ${ }^{13}$.

\section{Preliminary phytochemical analysis}

\section{Preparation of extract}

Cold extract of seeds of Abrus precatorius L., was prepared in six different solvents of varying polarity viz. petroleum ether, chloroform, acetone, ethanol, methanol and water ${ }^{14}$.

\section{Phytochemical screening}

Preliminary phytochemical screening for various secondary metabolites was performed using standard procedures ${ }^{15}$. 


\section{Optimization studies}

Extractive value was calculated in six different solvents of varying polarity to choose the best solvent for further extraction of plant sample ${ }^{16}$. The solvent with best solubility was then subjected to optimization studies for calculating amount of solvent, time duration of extraction and number of extraction required to give maximum yield.

\section{HPTLC fingerprinting}

\section{Sample preparation}

Methanolic extracts was obtained by sonication, as per the optimization studies and used for sample application.

\section{Developing solvent system}

Best resolution was obtained in the solvent Toluene: Chloroform: Ethanol (4:4:1 v/v/v).

\section{Sample application}

Chromatograph was performed on $20 \times 10 \mathrm{~cm}$ aluminium packed TLC plate coated with $0.2 \mathrm{~mm}$ layer of silica gel 60F254 ((E. Merck Ltd, Darmstadt, Germany) stored in a dessicator. $5 \mu \mathrm{L}$ aliquot of Abrus precatorius L. was used for the experiment. 5 Bands of $8 \mathrm{~mm}$ width, was applied by Hamilton microsyringe (Switzerland), with the nitrogen flow providing a delivery speed of $150 \mathrm{~nL} / \mathrm{s}$. The syringe was mounted on a Linomat $\mathrm{V}$ applicator (S/N: 080222) attached to CAMAG HPTLC Visualizer system (S/N 15503) and was programmed through WIN CATS software. Spotting was performed at $25 \pm 2{ }^{\circ} \mathrm{C}$ ascending development of the plate with elution distance of $80 \mathrm{~mm}$ (distance to the lower edge was $10 \mathrm{~mm}$ ).

\section{Development of chromatogram}

After the application of sample, the chromatogram was developed in Twin trough glass chamber $20 \times 10 \mathrm{~cm}$ saturated with solvent vapours of Toluene: Chloroform: Ethanol (4:4:1 $\mathrm{v} / \mathrm{v} / \mathrm{v}$ ) for 20 minutes. The linear ascending development was carried out and $20 \mathrm{~mL}$ of mobile phase was used per chromatography run.

\section{Detection of spots}

The developed plate was dried by hot air to evaporate solvents from the plate. The developed plate was sprayed with anisaldehyde sulphuric acid reagent as spray reagent and dried at $105{ }^{\circ} \mathrm{C}$ on heating plate for $3 \mathrm{~min}$.

\section{Photodocumentation}

The plate was kept in photodocumentation chamber (CAMAG Visualizer (S/N: 150503) and images were captured under UV light at $366 \mathrm{~nm}$ and visible light. The scanning was done by CAMAG Scanner 4 ( $\mathrm{S} / \mathrm{N}$ : 170422). The $\mathrm{R}_{\mathrm{f}}$ values and finger print data were recorded by WIN CATS software.

\section{FTIR fingerprinting}

The seed powder of the plant under study was grounded with $\mathrm{KBr}$ salt to obtain a translucent pellet. The analysis was carried out using 3000 Hyperion microscope with vertex 80 FTIR System. The transmittance spectra was analysed between $400-4000 / \mathrm{cm}$ wavenumber. 


\section{Results and Discussion}

\section{Proximate analysis}

Prolong or improper storage of herbal products can lead to change in their original characteristics. Proximate analysis of herbal samples is accepted by WHO (1998) as a quality control parameter. The result of proximate analysis carried out for the plant under study is given in Table 1.

Table 1. Proximate analysis of seeds of Abrus precatorius $\mathrm{L}$.

\begin{tabular}{clc}
\hline S.No & Parameters & \% Content \\
\hline 1 & Foreign organic matter & 0.71 \\
2 & Total ash & 5.33 \\
3 & Acid insoluble ash & 1.0 \\
4 & Water soluble ash & 3.17 \\
5 & Sulphated ash & 5.33 \\
6 & Loss on drying & 3.2 \\
7 & Crude fibre content & 79 \\
\hline
\end{tabular}

The present results indicate that the collected material contains $0.71 \%$ foreign organic matter and it is within the prescribed limit of $2 \%$ (API, 2000). The total ash content was $5.3 \%$ against the prescribed limit of $17 \%$ and acid soluble ash was found to be $1 \%$, much below the accepted level of 5\% (API, 2000). Similarly values of sulphated ash, loss of drying and crude content is also found to be well within the limit.

\section{Preliminary phytochemical analysis}

The result of qualitative phytochemical screening of various secondary metabolites is given in Table 2. The result shows that the plant is a good source of secondary metabolites. It also indicates that ethanol and methanol are the best solvents among various solvents used for extraction of secondary metabolites from the plant under study.

Table 2. Qualitative phytochemical screening of various extracts of Abrus precatorius $\mathrm{L}$.

\begin{tabular}{|c|c|c|c|c|c|c|c|}
\hline \multirow{2}{*}{$\begin{array}{c}\text { S. } \\
\text { No } \\
\end{array}$} & \multirow{2}{*}{ Tests of secondary metabolites } & \multicolumn{6}{|c|}{ Extraction solvents } \\
\hline & & P.E. & Chl. & Act. & $\mathrm{EtOH}$ & $\mathrm{MeOH}$ & W \\
\hline \multirow[t]{4}{*}{1.} & Alkaloids & & & & & & \\
\hline & Mayer's Test & + & + & - & + & + & - \\
\hline & Wagener's Test & + & + & - & + & + & - \\
\hline & Dragendroff's Test & + & + & - & + & + & - \\
\hline 2. & Glycosides & - & - & + & + & + & + \\
\hline 3. & Flavonoids & + & + & + & ++ & ++ & + \\
\hline 4. & Steroids (Liebermann-Burchard's test) & + & + & + & ++ & ++ & ++ \\
\hline 5. & Saponins (Foam test) & - & + & + & + & + & + \\
\hline 6. & Phytosterols & + & + & + & + & + & + \\
\hline 7. & Terpenoids & + & + & + & + & + & + \\
\hline 8. & Tannins & + & + & + & + & + & + \\
\hline 9. & Phenols (Lead acetate test) & + & + & + & + & + & + \\
\hline
\end{tabular}

The results of optimization studies are summarized in Table 3. The best solvent was found to be methanol as it was showing maximum extractive value than other solvents used for the 
experiment, under similar conditions. The ideal optimized condition for getting maximum extractive value is using $50 \mathrm{~mL}$ methanol twice for the duration of $90 \mathrm{~min}$.

Table 3. Optimized conditions for extractions of seeds of A. precatorius

\begin{tabular}{ccccc}
\hline Sample & Type of solvent & $\begin{array}{c}\text { Amount of } \\
\text { solvent }\end{array}$ & $\begin{array}{c}\text { Time for } \\
\text { extraction }\end{array}$ & $\begin{array}{c}\text { Number of } \\
\text { extraction }\end{array}$ \\
\hline $\begin{array}{c}\text { Abrus } \\
\text { precatorius L. }\end{array}$ & Methanol & $50 \mathrm{~mL}$ & $90 \mathrm{~min}$. & 2 \\
\hline
\end{tabular}

\section{HPTLC fingerprinting}

The methanolic extracts of Abrus precatorius L., was subjected to generate HPTLC finger printing profile represented as chromatogram. The solvent system used in the investigation was found to give compact spots for extracts at different $R_{\mathrm{f}}$ values and there was no overlap with any other component in the analyzed sample at $366 \mathrm{~nm}$ and visible light (Figure 1 and 2).

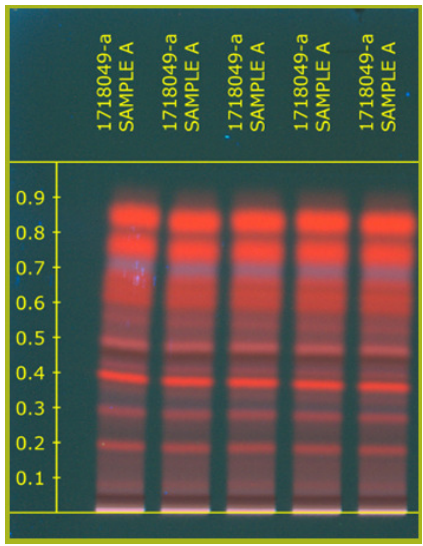

Figure 1. HPTLC fingerprint profile of Abrus precatorius $\mathrm{L}$, at $366 \mathrm{~nm}$ before derivatization (Plate 1)

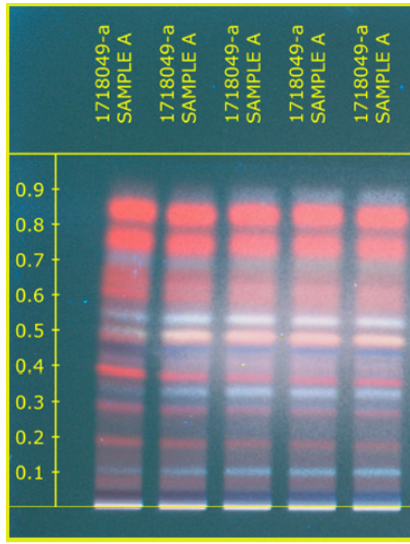

Figure 2. HPTLC fingerprint profile of Abrus precatorius $\mathrm{L}$, at $366 \mathrm{~nm}$ after derivatization (Plate 2)

The results from HPTLC finger print scanned at wavelength $366 \mathrm{~nm}$ for $5 \mu \mathrm{L}$ methanolic extract of seeds of Abrus precatorius L. (Figure 2) reveal the occurrence of eleven polyvalent phytoconstituents with corresponding ascending order of $\mathrm{R}_{\mathrm{f}}$ values as $0.04,0.14,0.21,0.31,0.36,0.40,0.44,0.51,0.56,0.77$ and 0.86 .

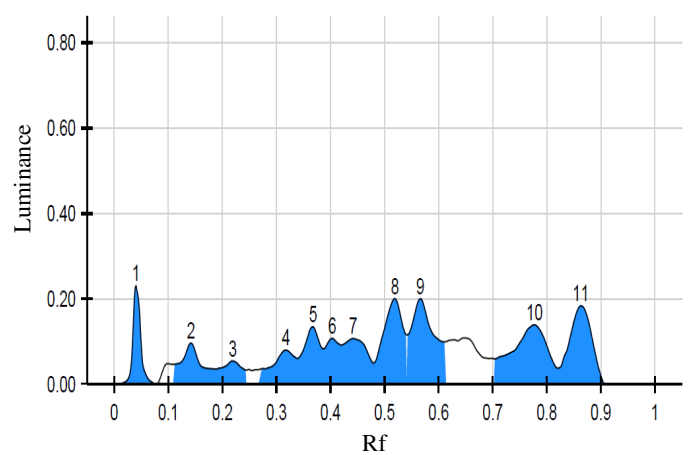

Figure 2. Densitogram of fingerprint profile of methanolic extract of A. precatorius $L$. 


\section{FTIR fingerprinting}

The FTIR spectrum was used to identify the functional group of the active components based on the peak value in the region of infrared radiation. Powdered material of Abrus precatorius $\mathrm{L}$., was passed into the FTIR and the functional groups of the components were separated based on its peak ratio (Figure 3 ).

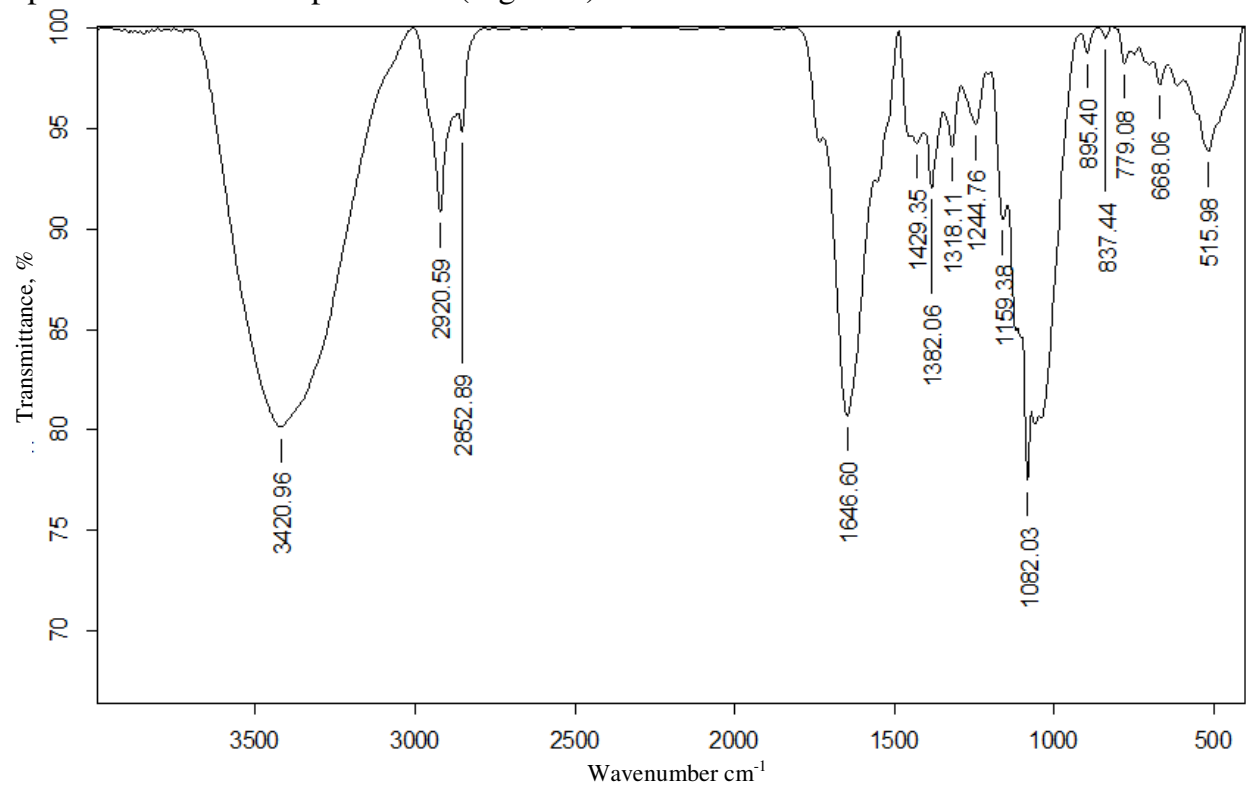

Figure 3. FTIR Spectrum of seeds of Abrus precatorius L.

The results of FTIR analysis for seeds of Abrus precatorius L. confirmed the presence of amines, amide, alcohols, phenols, alkanes, carboxylic acids, aldehydes, ketones, alkenes, primary amines, aromatics, esters, ethers, alkyl halides and aliphatic amines compounds (Figure 3; Table 4). Peaks were observed at 895.40, 837.44, 779.08, 668.06 and 515.98. Area $<1000 \mathrm{~cm}^{-1}$ corresponds to $\mathrm{C}-\mathrm{H}$ bending from isoprenoids. A major peak was observed at $1082.03 .997-1130 \mathrm{~cm}^{-1}$ corresponds to stretching vibration $\mathrm{C}-\mathrm{O}$ of mono and oligo carbohydrates. Two peaks were observed at 1159.38 and 1244.76 . Readings between $1150-1270 \mathrm{~cm}^{-1}$ corresponds to stretching vibrations of carbonyl C-O or OH bendings. Major peaks were also observed at 1318.11, 1382.06 and 1429.35. It is reported that peaks between $1300-1450 \mathrm{~cm}^{-1}$ corresponds to stretching vibrations of C-O (amides) and C-C stretching from phenyl group. Major peaks was observed at 1646.60 which lies between the range of $1600-1760 \mathrm{~cm}^{-1}$ corresponding to bending vibrations of $\mathrm{N}-\mathrm{H}$ (amino acids) indicating high protein content ${ }^{17}$ and $\mathrm{C}=\mathrm{O}$ stretching (aldehyde and ketone esters). 2800-2900 $\mathrm{cm}^{-1}$ corresponds to $\mathrm{C}-\mathrm{H}$ stretching vibrations specific to $\mathrm{CH}_{3}$ and $\mathrm{CH}_{2}$ from lipids, methoxy derivatives, $\mathrm{C}-\mathrm{H}$ (aldehydes) including cis double bonds. A peak was observed at 2852.89 indicating the presence of $\mathrm{O}-\mathrm{H}$ carboxylic group. A peak at 2920.59 indicates $\mathrm{O}-\mathrm{H}$ carboxylic acids. A peak at 3420.96 indicated $\mathrm{N}-\mathrm{H}$ (amines) stretching. This lies in the range between $3350-3600 \mathrm{~cm}^{-1}$ corresponds to stretching vibrations of $\mathrm{OH}$ groups from water, alcohols, phenols, carbohydrates, peroxides as well as from amides ${ }^{18}$. No absorbance between 2220-2260 indicates that no cyanide is present indicating absence of toxic substances ${ }^{17}$. 
Table 4. Wavenumber $\left(\mathrm{cm}^{-1}\right)$ of dominant peak obtained from absorption spectra of seeds of Abrus precatorius $\mathrm{L}$.

\begin{tabular}{cl}
\hline $\begin{array}{c}\text { Wave number of dominant } \\
\text { peak, } \mathrm{cm}^{-1}\end{array}$ & \multicolumn{1}{c}{ Functional groups and bond stretching } \\
\hline 3420.96 & N-H stretching (amines) \\
2920.59 & O-H (carboxylic acid) \\
2852.89 & O-H (carboxylic acid) \\
1646.60 & C-O (alkenes) \\
1429.35 & C-O (amide), C-C stretching (phenyl) \\
1382.06 & C-OH (alcohol) \\
1318.11 & N-acetylglucosamine (Chitin) \\
1244.76 & C-O (carbonyl), O-H bendings \\
& Symmetric bonding of aliphatic $\mathrm{CH}_{2} \mathrm{OH}$ or \\
1159.38 & $\mathrm{C}-\mathrm{O}$ stretch of various groups of cell wall \\
& polysaccharides \\
1082.03 & C-O (mono \& oligo carbohydrates) \\
895.40 & C-H bendings from isoprenoids \\
837.44 & Characteristic absorption of polysaccharides \\
779.08 & C-H aromatics \\
668.06 & C-X alkenes \\
515.98 & Halogens \\
\hline
\end{tabular}

\section{Conclusion}

The proximate analysis of plant part will help to determine the specificity and purity when used for drug preparation. The optimized extraction procedure in this research work can be used for ensuring maximum possible use of the crude drug on one hand and will avoid wastage of solvent and other resources used for extraction. Understanding from the results, methanol is used as extracting solvent for this plant in the present work. The medicinal properties exhibited by the plant can be attributed to the presence of various classes of secondary metabolites. Development of HPTLC fingerprint which will serve for standardization and authentication of the plant and also as a biomarker. The standardized FTIR spectrum may be employed as a molecular fingerprint of the plant.

\section{References}

1. Donno D, Boggia R, Zunin P, Cerutti A K, Guido M, Mellano M G and Beccaro G L, $J$ Food Sci Technol., 2016, 53(2), 1071-1083; DOI:10.1007/s13197-015-2115-6

2. Amit Saraf K, Srilata Srinivas and Alka Chaturvedi, Res J Pharm Biol Chem Sci., 2016, 7(4), 471-476.

3. Reich E and Schibli A, High-Performance Thin-Layer Chromatography for the Analysis of Medicinal Plants. Thieme; 2007.

4. Saraf A and Saraf A, Int J Pharm Phytochem Res., 2014, 6(2), 213-222.

5. Malhi B S and Trivedi V P, Quarter J Crude Drug Res., 1972, 12(3), 1922-1928; DOI:10.3109/13880207209068244

6. Agarwal S S, Ghatak N, Arora R B and Bhardwaj M M, Pharmacol Res Commun., 1970, 2(2), 159-164; DOI:10.1016/S0031-6989(70)80024-8

7. Munsho S R, Shetye T A and Nair R K, Planta Med., 1977, 31(1), 73-75; DOI:10.1055/s-0028-1097494 
8. $\quad$ Nath D, Sethi N, Singh R K and Jain A K. J Ethnopharmacol, 1992, 36(2), 147-154; DOI:10.1016/0378-8741(92)90015-J

9. Chopra R N, Indigenous Drugs of India. Their Medical and Economic Aspects. The Art Press, Calcutta, India, 1933, 550.

10. Jamwal K S and Anand K K, Indian J Pharm., 1962, 24(9), 218-220.

11. Priya G, Saravanan K and Renuka C, Int J PharmTech Res., 2012, 4(1), 481-94.

12. Bagaria A, Surendranath K, Ramagopal U A, Ramakumar S and Karande A A, $J$ Biolog Chem., 2006, 281(45), 34465-34474.

13. Ayurvedic Pharmacopoeia of India (API, Part I, Vol. IX, 2016) (http://ayush.gov.in/sites/default/files/Ayurvedic\%20Pharmacopoeia\%20of\%20India \%20part\%201\%20volume\%20IX.pdf)

14. Kokate C K, Purohit A P and Gokhale S B, Pharmacognosy. Nirali Prakashan, Pune, 2006, 133-525.

15. Harborne J B, Methods Plant Biochem., 1989, 1, 1-28; DOI:10.1016/B978-0-12461011-8.50007-X

16. IHP, 2002; The Ayurvedic Pharmacopoeia of India, 2000 http://www.ayurveda.hu/api/API-Vol-2.pdf

17. Ragavendran P, Sophia D, Arul Raj C and Gopalakrishnan V K, Pharmacologyonline, 2011, 1, 358-364.

18. Zavoi S, Fetea F, Ranga F, Raluca M P, Baciu A and Socaciu C, Notulae Botanicae Horti Agrobotanici Cluj-Napoca, 2011, 39(2), 82-89; DOI:10.15835/nbha3926278 